\title{
New Disease Reports \\ First report of stem blight of asparagus caused by Phomopsis asparagi in Myanmar
}

\author{
M. Zaw ${ }^{1}$, T.A.A. Naing ${ }^{2}$ and M. Matsumoto ${ }^{1 *}$ \\ ${ }^{1}$ Institute of Tropical Agriculture, Kyushu University, Fukuoka, 812-8581, Japan; ${ }^{2}$ Department of Plant Pathology, Yezin \\ Agricultural University, Myanmar
}

*E-mail: mmatsu@agr.kyushu-u.ac.jp

Received: 20 Feb 2017. Published: 19 Apr 2017. Keywords: alpha-conidia, conidiomata, fungal plant disease

\begin{abstract}
Recently, asparagus (Asparagus officinalis) growing has become popular in Myanmar and it has been widely cultivated in the central lowlands and eastern mountainous regions of the country. In 2015 the crop was grown on approximately 900 ha, more than twice the area grown in 2010. In 2016, approximately 65 to $80 \%$ of plants in asparagus fields near Pyinmana were damaged by a plant disease which had symptoms similar to those of asparagus stem blight (Fig 1). Initially the individual lesions were oval shaped and $1.0-4.3 \mathrm{~cm}$ in length with concentric rings of pycnidia on the stem of the plant (Fig. 2). Later the lesions coalesced and the stem collapsed when weather conditions were favourable for development of the disease.
\end{abstract}

Diseased samples were collected and the fungal pathogen was isolated by culturing on $2 \%$ water agar media. The plates were incubated at $26^{\circ} \mathrm{C}$ for one day, and the emerged mycelium tip was transferred onto potato dextrose agar (PDA). The fungus produced black globose conidiomata (Fig. 3) containing alpha-conidia (Fig. 4). The mean length and width of alphaconidia were $8.4 \pm 1.1 \mu \mathrm{m}$ and $3.3 \pm 1.0 \mu \mathrm{m}$ respectively. Based on the morphological characteristics, the fungus was initially identified as Phomopsis asparagi (Uecker \& Johnson 1991).

Molecular characterisation of two fungal isolates was based on rDNA-ITS sequencing with the primers ITS1 and ITS4, and the sequence of each (GenBank Accession Nos. LC203583 and LC203585) had 99 and 100\% identity with a reference sequence of $P$. asparagi (KJ801806) causing stem blight of asparagus in China. Confirmation of the causal agent was completed by a pathogenicity test. A disc of mycelium $(5 \mathrm{~mm})$ was cut from a fourteen-day-old PDA culture, put on a stem of asparagus and covered with wet cotton, paraffin film and a plastic sheet to conserve moisture. Inoculation with a PDA disc was used as control. Fourteen days after inoculation, typical stem blight symptoms were observed on the inoculated stem with numerous black pycnidia. Koch's postulates were fulfilled by re-isolation of $P$. asparagi from the inoculated plants.

Phomopsis stem blight of Asparagus caused by $P$. asparagi has been recorded in most asparagus-growing countries in Africa, Asia, Australasia, Europe and North America (Elena, 2007). This is the first report of stem blight of asparagus caused by $P$. asparagi in Myanmar. As asparagus growing develops in Myanmar, there is an increasing risk of an outbreak of stem blight. Further research on disease management is needed in Myanmar

\section{References}

Elena K, 2007. Asparagus diseases. The European Journal of Plant Science and Biotechnology 1, 76-83.

Uecker FA, Johnson DA, 1991. Morphology and taxonomy of species of Phomopsis on Asparagus. Mycologia 83, 192-199.

http://dx.doi.org/10.2307/3759934

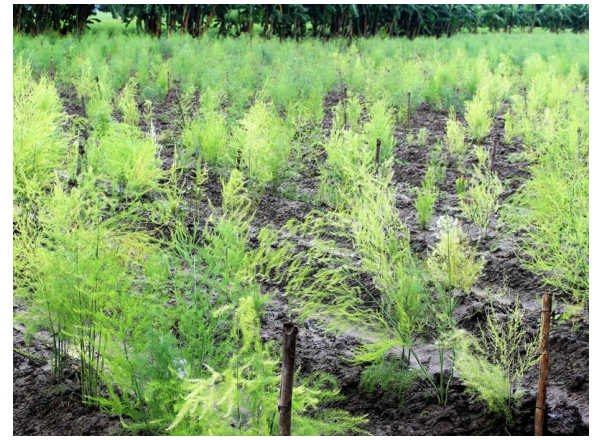

Figure 1

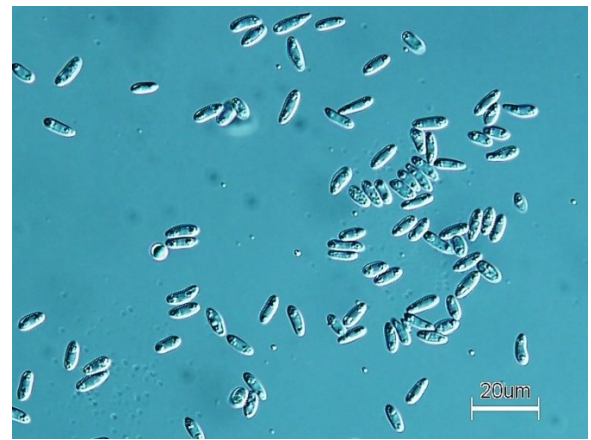

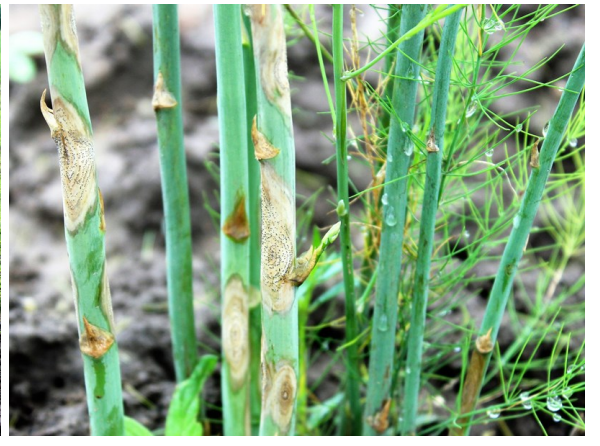

Figure 2

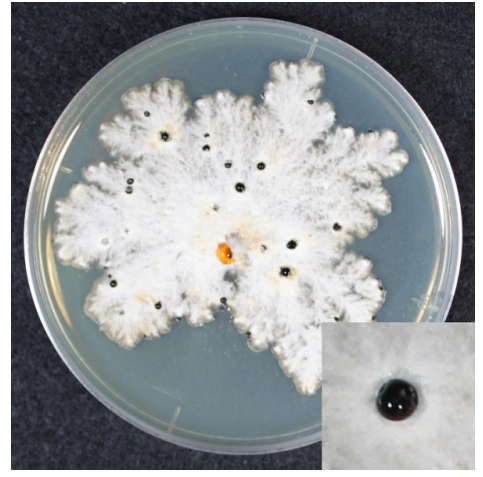

Figure 3

Figure 4

To cite this report: Zaw M, Naing TAA, Matsumoto M, 2017. First report of stem blight of asparagus caused by Phomopsis asparagi in Myanmar. New Disease Reports 35, 17. http://dx.doi.org/10.5197/j.2044-0588.2017.035.017

(c) 2017 The Authors

This report was published on-line at www.ndrs.org.uk where high quality versions of the figures can be found. 